\title{
Effect of glycine and glucose on sodium and water absorption in patients with cholera
}

\author{
D. R. NALIN, R. A. CASH, M. RAHMAN, AND MD. YUNUS \\ From the Pakistan-SEATO Cholera Research Laboratory, GPO Box 128, Dacca, East Pakistan
}

\begin{abstract}
SUMMARY Electrolyte solutions containing glucose, glycine, or a combination of the two were absorbed sufficiently well from the intestine to supply maintenance fluid and the electrolytes required by cholera patients. Data on net absorption and duration and volume of diarrhoea show that a solution containing both glucose and glycine provides more effective therapy than solutions containing either glucose or glycine alone.
\end{abstract}

Individual amino acids which are actively transported are known to increase in vitro the mucosato-serosa sodium flux in the jejunum and ileum and to increase in vivo the lumen-to-plasma flux. Several workers have shown that the increase in vivo and in vitro in intestinal sodium absorption induced by a combination of an actively transported sugar with an actively transported amino acid is greater than that induced by either substrate alone (Esposito, Faelli, and Capraro, 1964; Schultz and Zalusky, 1965; Adibi, 1967; Annegers, 1966; Grady, Madoff, Duhamel, Moore, and Chalmers, 1967; Fordtran, Rector, and Carter, 1968). The present study was designed to determine whether glycine, one of the amino acids which increases the lumen-to-plasma sodium flux, would promote net sodium and water absorption in cholera patients. When this was established additional balance studies were carried out using an oral maintenance solution containing both glucose and glycine.

\section{Patients and Methods}

INITIAL BALANCE STUDIES

Forty-eight patients who were severely dehydrated were selected for these studies. The diagnosis of cholera was confirmed by culture of

Received for publication 12 January 1970. daily rectal swabs. The severity of the dehydration was determined by measuring the specific gravity of plasma obtained on admission. The patients were treated with a standard intravenous fluid. When blood pressure became normal, the specific gravity of plasma was checked after each $500 \mathrm{ml}$ of intravenous fluid until it was less than 1.030. Then intravenous therapy was stopped and an oral or nasogastric solution was started. Specific gravity of plasma was checked every four hours thereafter, and more intravenous fluid was provided if the specific gravity rose above 1.030.

The four therapy groups were treated with oral or intragastric solutions containing (1) electrolytes, (2) electrolytes with glycine, (3) electrolytes with glucose, or (4) electrolytes with glucose plus glycine. The oral solutions were kept at $40^{\circ} \mathrm{C}$ during administration (Love, 1966). The composition of the fluid administered to the various groups is given in Table $\mathbf{I}$.

Early in the study it was realized that solutions containing less than $15 \mathrm{~m}$-equiv/l potassium did not maintain a positive potassium balance in adults, so the potassium content of the solutions was increased; in the glucose plus glycine balance studies, the concentration of sodium chloride was slightly decreased to offset the increased osmolarity of the solution.

Clinical and laboratory criteria of severity at the time of admission were similar in all groups (Table II). Data on the severity of disease in the oral glucose group have already been 


\begin{tabular}{lrrrr}
\hline & \multicolumn{3}{l}{ Solution } \\
\cline { 2 - 5 } & Plain & Glycine & Glucose & $\begin{array}{l}\text { Glucose }+ \\
\text { Glycine }\end{array}$ \\
\hline No. of patients & 9 & 12 & 17 & 10 \\
Na (m-equiv/l) & 120 & 120 & 120 & 100 \\
K (m-equiv/l) & 15 & 15 & $6 / 9^{1}$ & 15 \\
HCO (m-equiv/l) & 48 & 48 & 48 & 48 \\
Cl (m-equiv/l) & 72 & 72 & $78 / 72^{1}$ & 52 \\
Citrate (m-equiv/l) & 15 & 15 & $0 / 9^{1}$ & 15 \\
Glycine (m-mols/l) & - & 110 & -110 & 110 \\
Glucose (m-mols/l) & - & - & 110 & 110 \\
\hline
\end{tabular}

Table I Composition of oral solutions in the balance studies

${ }^{1}$ In the glucose group nine patients received a solution containing $6 \mathrm{~m}$-equiv/l of potassium as $\mathrm{KCl}$, and eight received $9 \mathrm{~m}$-equiv/1 of potassium as $\mathrm{K}$ citrate.

\begin{tabular}{|c|c|c|c|}
\hline & \multicolumn{3}{|l|}{ Solution } \\
\hline & Plain & Glycine & Glucose + Glycine \\
\hline $\begin{array}{l}\text { Males } \\
\text { Females } \\
\text { Age (yr) } \\
\text { Weight on admission }(\mathrm{kg}) \\
\text { Specific gravity of plasma } \\
\text { on admission } \\
\text { Venous bicarbonate on } \\
\text { admission (m-equiv/l) } \\
\text { Duration of diarrhoea } \\
\text { before admission (hr) }\end{array}$ & $\begin{array}{l}9 \\
31(20-53)^{1} \\
41(32-43) \\
1 \cdot 0395(1 \cdot 037 \cdot 1 \cdot 044) \\
16 \cdot 7(15-20 \cdot 2) \\
10(7-28)\end{array}$ & $\begin{array}{l}6 \\
6 \\
24(12-50) \\
38(21-47) \\
1 \cdot 039(1 \cdot 033-1 \cdot 046) \\
16(12-19 \cdot 8) \\
11(4-44)\end{array}$ & $\begin{array}{l}6 \\
4 \\
25(17-33) \\
40(28-50) \\
1.043(1 \cdot 031-1 \cdot 047) \\
16(8-23) \\
8(4-12)\end{array}$ \\
\hline
\end{tabular}

Table II Characteristics of the patients included in the initial balance studies

${ }^{1}$ Figures in parentheses give averages with range.

published (Nalin, Cash, Islam, Molla, and Phillips, 1968). All patients received $250 \mathrm{mg}$ tetracycline orally in syrup within one hour after admission and every six hours thereafter. Patients received nothing by mouth except the oral solution and tetracycline. The mean interval from admission until the daily rectal swab culture first became negative for Vibrio cholerae was less than two days in all groups.

The net gut balance was calculated every four hours by subtracting vomitus and stool volume from oral or intragastric intake. During the first four-hour period patients weighing less than $25 \mathrm{~kg}$ received $500 \mathrm{ml}$ of oral solution per hour and patients weighing more than $25 \mathrm{~kg}$ received $750 \mathrm{ml}$ per hour. If the balance during the first four hours indicated a fluid requirement greater than that estimated on admission, oral therapy was increased.

The amount of fluid given during each subsequent four-hour period approximately equalled the volume of stool and vomitus of the previous four-hour period. The maximum rate of administration was $1,500 \mathrm{ml} / \mathrm{hr}$, and studies ended when the rate of diarrhoea was less than $75 \mathrm{ml} /$ hour.

Aliquots of venous plasma, stool, and urine were analysed every four hours by standard method for electrolytes, urea, and creatinine.
CLINICAL TRIAL AT FIELD HOSPITAL

One hundred and thirty-six patients admitted for treatment of severe dehydration due to cholera were studied. Patients were rehydrated with intravenous fluid until the blood pressure was normal after which they were maintained on an oral solution. Alternate patients were given an oral solution of electrolytes with glucose or one with glucose and glycine; half of the patients treated with the oral glucose solution received $110 \mathrm{~m}$-mols/l of glucose and half received $220 \mathrm{~m}$-mols/l (Table III), but since no difference in the response of the patients could be detected, the results obtained with the two concentrations of glucose were averaged together.

\begin{tabular}{lcc}
\hline & \multicolumn{2}{c}{ Solution } \\
\cline { 2 - 3 } & Glucose & Glucose + Glycine \\
\hline No. of patients & 68 & 68 \\
Na (m-equiv/l) & 120 & 120 \\
K (m-equiv/l) & 25 & 25 \\
HCO (m-equiv/l) & 48 & 48 \\
Cl (m-equiv/l) & 72 & 72 \\
Citrate (m-equiv/l) & 25 & 25 \\
Glycine (m-mols/l) & - & 110 \\
Glucose (m-mols/l) & $110 / 220$ & 110 \\
\hline
\end{tabular}

Table III Composition of oral solutions in the clinical trial

The method of therapy was the same as that used in the balance studies, except that intake and output were calculated at six-hourly intervals. No laboratory tests are done at our field hospital, so that intake and output data and the return of normal clinical signs (pulse, blood pressure, skin turgor) were used as criteria for discontinuing intravenous fluid and starting oral therapy.

\section{Results}

The relationship of intravenous and oral fluid requirements to stool volume in three groups is shown in Fig. 1, which shows the greater volume of diarrhoea associated with the plain electrolyte infusion. Oral solutions containing glucose, glycine, or glucose plus glycine were absorbed in sufficient quantity to maintain fluid and electrolyte balance. The 3 to 4 litres of intravenous fluid required by severely dehydrated patients is the amount needed to correct shock at the time of admission.

Patients in the plain electrolyte group remained in negative water and sodium balance for over 20 hours and required relatively large amounts of intravenous fluid for maintenance.

After the start of oral therapy glycine absorption became evident by a sharp rise in serum urea nitrogen (mean increase $12 \mathrm{mg} \%$ by the 12 th hour) in all patients receiving the glycine 


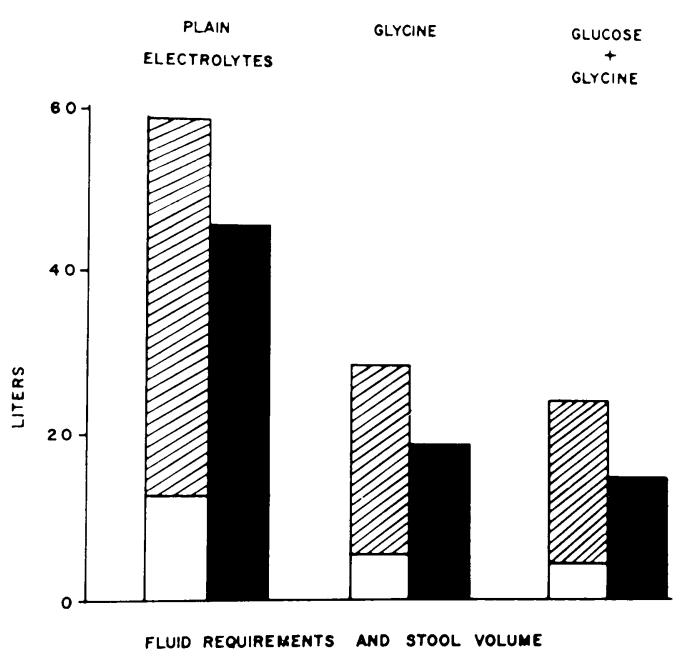

Fig. 1. The average total intake and output in three series of studies. Failure to absorb the plain electrolyte solution resulted in greatly increased diarrhoea volumes. Best absorption of the oral solutions occurred in patients who received the glycine-with-glucose solution. This resulted in lower diarrhoea volume. Intravenous fluid is shown by the unshaded area, oral fluid by the shaded area, and stool by the black area.
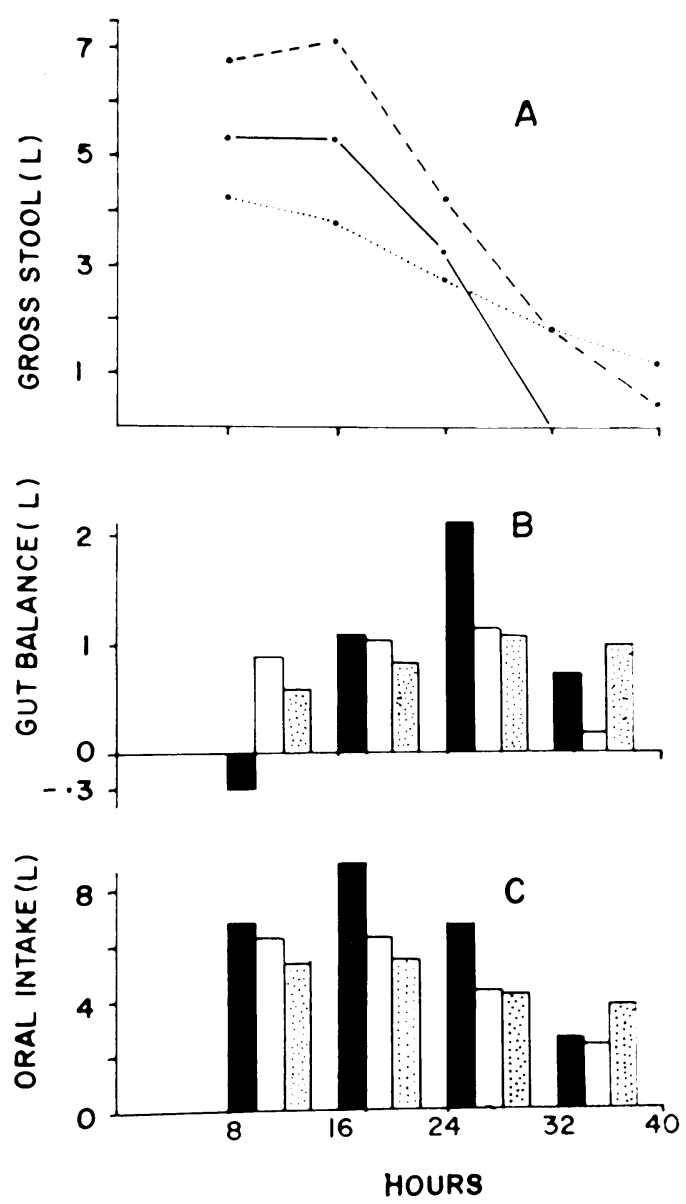

Fig. 2. Average gross stool volume (A), gut balance (B), and oral intake (C) during successive eight-hour periods in three study groups. (A) The shortest duration of diarrhoea occurred in the combined glucose-glycine group. (B) While duration was relatively short in the glycine group, mean net balance remained negative during the first eight hours. (C) Since diarrhoea over $75 \mathrm{ml} / \mathrm{hr}$ persisted in the glucose group for a mean of 44 hours (not shown), oral therapy was necessary for a relatively long period when the glucose solution was used.

Glycine shown by the black area and the broken line, glucose plus glycine by white area and solid line, and glucose alone by the shaded area and dotted line. red in some patients who received less than 15 m-equiv/l of potassium in the oral solution. A decrease in serum sodium and chloride concentrations occurred in six patients in the plain electrolyte group. Bicarbonate levels frequently were elevated after 16 hours of oral therapy, but patients with serum bicarbonate concentrations of 30 to 38 m-equiv/l at the end of the diarrhoea period had no associated morbidity except for one patient with hypocalcaemia who developed tetany.

Figure 2 shows the volume of diarrhoea, net gut balance, and oral intake of three groups during the first 40 hours of the study. During the first eight hours net absorption was greatest in 


\begin{tabular}{|c|c|c|c|c|}
\hline & \multicolumn{4}{|l|}{ Solution } \\
\hline & Plain & Glucose & Glycine & $\begin{array}{l}\text { Glucose }+ \\
\text { Glycine }\end{array}$ \\
\hline $\begin{array}{l}\mathrm{H}_{2} \mathrm{O}(\mathrm{ml}) \\
\mathrm{Na}(\mathrm{m} \text {-equiv/l) } \\
\mathrm{K} \text { (m-equiv/l) } \\
\mathrm{Cl} \text { (m-equiv/l) }\end{array}$ & $\begin{array}{l}-1,400(-3) \\
-\quad 510(-0.9) \\
140(20 \cdot 0) \\
-\quad 630(-2 \cdot 1)\end{array}$ & $\begin{array}{c}5,000(26 \cdot 6) \\
420(21 \cdot 0) \\
-10(-21 \cdot 5) \\
250(29 \cdot 6)\end{array}$ & $\begin{array}{r}3,600(18 \cdot 9) \\
490(21 \cdot 6) \\
70(19 \cdot 1) \\
280(21 \cdot 7)\end{array}$ & $\begin{array}{r}5,200(30 \cdot 4) \\
400(22 \cdot 3) \\
60(25 \cdot 9) \\
90(12 \cdot 4)\end{array}$ \\
\hline
\end{tabular}

Table IV Mean net electrolyte and water absorption in initial balance studies

The relatively lower positive chloride balance in the glucoseglycine group was due primarily to the lower amount of chloride in the solution given to this group.

Figures in parentheses give the net absorption expressed as percentage.

and 27 hours in the glucose plus glycine group. There were significant differences between the group taking the plain electrolyte solution and those on glucose or glycine $(P<0.05)$, and between those taking the plain electrolyte solution and glucose plus glycine $(\mathrm{P}<0.01)$.

Table IV indicates that the net percentage of absorption of oral solution was highest in the glucose plus glycine group. However, the oral solutions containing only glucose or glycine were absorbed sufficiently well to supply maintenance fluid and electrolyte requirements. Patients treated with glucose or glycine usually achieved a positive water and electrolyte balance within the first eight to 12 hours of oral therapy.

The results of the Matlab field trial (Table V) confirmed the results of the previous balance studies. The mean requirement of intravenous fluid was 3 litres. The severity of disease in the 68 patients in each group was similar at the time of admission, but the duration of diarrhoea of the patients on glucose plus glycine was nine hours less and the diarrhoea volume 6 litres lower than for the glucose group. These differences were significant $(\mathrm{P}<0.05)$.

\begin{tabular}{lll}
\hline & \multicolumn{2}{l}{ Solution } \\
\cline { 2 - 3 } & Glucose & Glucose + Glycine \\
\hline No. of patients & 68 & 68 \\
Age (yr) & $30 \cdot 5$ & $32 \cdot 5$ \\
Weight when discharged (kg) & 40 & 40 \\
No. admitted in shock (\%) & 75 & 75 \\
Diarrhoea volume (l) & $15 \cdot 5$ & $9 \cdot 5$ \\
Duration (hr) & 38 & 29 \\
\hline
\end{tabular}

Table V Clinical trial

Half of the patients in the glucose group received the solution containing $110 \mathrm{~m}$-mols $/ 1$ of glucose and one half received a solution of $220 \mathrm{~m}$-mols/litre.

\section{Discussion}

For patients with severe cholera, early maintenance of a positive sodium and water balance by means of oral therapy requires an oral solution containing additional substances, such as glycine, glucose, or galactose, which increase the sodium absorption. This and previous studies indicate that any sugar or amino acid which enhances sodium absorption will probably promote sodium absorption in cholera patients (Nalin et al, 1968; Hirschhorn, Kinzie, Sachar, Northrup, Taylor, Ahmad, and Phillips, 1968; Taylor, Hare, and Phillips, 1968; Phillips, 1964).

Previously we reported that cholera patients treated with an oral solution of electrolytes and glucose needed $80 \%$ less intravenous therapy than similar patients who received intravenous therapy alone (Nalin, Cash, Islam, Molla, and Phillips, 1968). Since the results of treatment with the glycine and the glucose solutions are similar, it may be concluded that a comparable reduction in the necessary intravenous fluid can be obtained using the glycine solution as oral maintenance therapy for cholera.

Our results show that in cholera patients glucose and glycine have an additive effect, since sodium and water absorption was greatest during the acute phase in the group treated with the combined solution. The increase in absorption was associated with the shortest duration of diarrhoea of the groups studied. The clinical trial established the practical advantages of the glucose plus glycine solution by confirming in the field the relatively short duration of diarrhoea and associated decrease of diarrhoea volume which occur when the combined solution is used. This has the advantage that it shortens the time of the patient's stay in hospital and also the time spent by the staff on each patient.

We wish to thank Miss Dorothy Torrance and the nursing staffs of the Pakistan-SEATO Cholera Research Laboratory and Matlab Field Hospital for their invaluable assistance in carrying out this study.

These studies were supported in part by research agreement no. 196802 between the National Institutes of Health, Bethesda, Maryland, USA, and the Pakistan-SEATO Cholera Research Laboratory, Dacca, East Pakistan.

The Pakistan-SEATO Cholera Research Laboratory is a part of the SEATO Cholera Research Program and is supported by the US Agency for International Development, Department of State, the National Institutes of Health, and the National Communicable Disease Center of the Department of Health, Education and Welfare, and by the Governments of Pakistan, United Kingdom, and other SEATO nations. The NIH Cholera Advisory Committee coordinates the research programme. 


\section{References}

Adibi, S. A. (1967). The interrelationship between leucine absorption rate and net $\mathrm{na}^{+}$and water fluxes in the human jejunum. Clin. Res., 15, 458.

Annegers, J. H. (1966). Some effects of hexoses on the absorption of amino acids. Amer. J. Physiol., 210, 701-704.

Esposito, G., Faelli, A., and Capraro, V. (1964). Influence of the transport of amino acids on glucose and sodium transport across the small intestine of the Albino rat incubated in vitro. Experientia (Basel), 20, 122-124.

Fordtran, J. S., Rector, F. C., Jr., and Carter, N. W. (1968) The mechanisms of sodium absorption in the human small intestine. J. clin. Invest., 47, 884-900.

Grady, G. F., Madoff, M. A., Duhamel, R. C., Moore, E. W., and Chalmers, T. C. (1967). Sodium transport by human ileum in vitro and its response to cholera enterotoxin. Gastroenterology, 53, 737-744.

Hirschhorn, N., Kinzie, J. L., Sachar, D. B., Northrup, R. S. Taylor, J. O., Ahmad, S. Z., and Phillips, R. A. (1968).
Decrease in net stool output in cholera during intestinal perfusion with glucose-containing solutions. New Engl. J. Med., 279, 176-181.

Love, A. H. G. (1966). The influence of the temperature of intraluminal contents on fluid transit and absorption in the human intestine. J. Physiol. (Lond.), 185, 80P.

Nalin, D. R., Cash, R. A., Islam, R., Molla, M., and Phillips, R. A. (1968). Oral maintenance therapy for cholera in adults. Lancet, $2,370-372$.

Peters, J. P., and van Slyke, D. D. (1946) Quantitative Clinical Chemistry, vol 1, 794-797. Williams and Wilkins; Baltimore, Bailliére, London.

Phillips, R. A. (1964). Water and electrolyte losses in cholera. Fed. Proc., 23, 705-712.

Schultz, S. G., and Zalusky, R. (1965). Interactions between active sodium transport and active amino acid transport in isolated rabbit ileum. Nature (Lond.), 205, 292-294.

Taylor, J. O., Hare, R. S., and Phillips, R. A. (1968). Measurement of sodium fluxes in human small intestine. Fed. Proc., 27, 386.

\section{(1) \\ ॄ

